\title{
Simulated training model in a low cost for laparoscopic inguinal hernioplasty
}

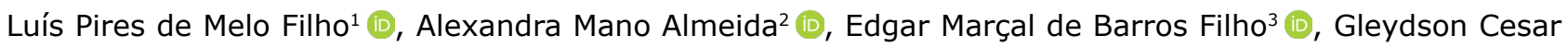
de Oliveira Borges ${ }^{4}$ (D)

1.MD. Santa Casa de Misericórdia de Fortaleza - Department of General Surgery - Fortaleza (Ceará), Brazil.

2.MD. Santa Casa de Misericórdia de Fortaleza - Department of General Surgery - Fortaleza (Ceará), Brazil.

3.PhD. Centro Universitário Christus - Postgraduate Program in Computer Science - Fortaleza (Ceará), Brazil.

4. MD. Centro Universitário Christus - Professional Master`s Degree in Minimally Invasive Technology and Simulation in the Health field- Fortaleza (Ceará), Brazil.

\begin{abstract}
Purpose: Develop a 3D model for the simulation of laparoscopic inguinal hernioplasty transabdominal preperitoneal (TAPP). Methods: This is an experimental study, 18 participants were selected, divided into three groups, experimental (GE) surgeons in training, control (GC) experienced surgeons and Shaw (GS) nonexperienced surgeons. The simulation in the 3D model was carried out in 6 sessions fulfilling the 5 stages. Opening the peritoneum with the creation of the preperitoneal space; identification of important structures; hernia identification and reduction; placement and fixation of the mesh in Cooper's ligament and closure of the peritoneum. Results: In the 1st stage, the GE obtained an average of $1.25 \pm 0.42$ in the 1st session and $3.25 \pm 0.62$ in the 6th session $(p=0.05)$ and in the 5th stage $0.91 \pm 0.29$ in the first session. 1st session and $1.91 \pm 0.29$ in the 6th session $(p=0.001)$, with no significant difference between groups. The learning and skill curve in the SG represented $1.08 \pm 0.291$ st and $3.50 \pm 0.906$ th session $(p=0.001)$. Conclusion: The creation of a systematization of training in simulation applied to the three-dimensional model enabled gain in laparoscopic skills and underpinned its theoretical and practical foundations.
\end{abstract}

Key words: Inguinal Hernia. Laparoscopy. Simulation Training. Health Education. Three-Dimensional Printing.

*Corresponding author: luisfilho4@hotmail.com | (55 85)9912-2210

Received: Sept 17, 2020 | Review: Nov 16, 2020 | Accepted: Dec 19, 2020

Conflict of interest: Nothing to declare.

Research performed at Department of General Surgery, Santa Casa de Misericórdia de Fortaleza, Fortaleza-CE, Brazil. 


\section{Introduction}

Inguinal hernia is a pathology described as a public health problem due to its prevalence in the adult population ${ }^{1}$. Its prevalence is estimated from 5 to $18 \%$ and the incidence reaches from 100 to 300 cases per 100,000 inhabitants yearly worldwide, being the inguinal hernioplasty the most commonly performed abdominal surgery ${ }^{2-4}$. Laparoscopic correction of inguinal hernias became popular in the 1990s when Ger first described this approach ${ }^{5}$. In the same decade, Maurice Arregui described the technique that combined the principles of the French school (STOPPA) with the new minimally invasive approach being named as transabdominal preperitoneal (TAPP) ${ }^{6}$.

The literature describes laparoscopy as an effective approach, reducing cost of painkillers, intraoperative and long-term complications such as seroma, numbness, and pain $^{7-9}$. Even with the most serious complications being rare, they are intestinal perforations and large vessel lesions. Bladder lesion is more common, corresponding to $0.2 \%$, being more frequent in patients with anterior suprapubic surgery ${ }^{10}$. Even with an effective approach the procedure cost became limiting, both in the procedure and in the learning curve ${ }^{11}$. But with the spread of knowledge and experience, it was possible to adapt and improve these factors, and with favorable patient performance due to lower metabolic response to trauma, early hospital discharge, rapid return to work, reduced days off due to disability, laparoscopy becomes an effective and efficient method that can provide better patient safety ${ }^{11-12}$.

The simulated training (ST) in laparoscopy demonstrates several benefits for not intervening in the patient, where both experienced surgeons and those in training can learn ${ }^{13}$. A cognitive and technical training curriculum is important for the optimization of surgeon skills. Thus, the availability of ST should be as early as possible to develop the necessary skills ${ }^{14}$. Therefore, this study aimed to develop a three-dimensional (3D) model for the simulation of TAPP laparoscopic inguinal hernioplasty and to evaluate its application in three groups of surgeons.

\section{Methods}

This is an experimental study, developed and applied at the Laboratory of Surgical Skills (LSS) and the Laboratory of Technological Innovation (LTI) of Centro Universitário Unichristus. The sample was characterized by surgeons, divided into three groups, experimental group (EG) surgeons in training, control group (CG) experienced surgeons and Shaw group (SG) surgeons not experienced.

\section{Intervention description}

The sessions were supervised by a research surgeon passively, without any intervention during the execution of the curriculum stages by the surgeons in training participating in the research. His function was strictly to measure the surgical time, record the session as described in the methodology and receive the forms. Participants had early access to the curriculum (Fig. 1), being able to read and clarify doubts in the execution steps and then watched the video exemplifying the execution of the curriculum in the HerniLap 3D model.

The ST developed in this study included five steps (Step 1: opening of the peritoneum to create the preperitoneal space; Step 2: identification of structures; Step 3: identification and reduction of the hernia; Step 4: mesh placing and fixing and Step 5: peritoneum closure, shown in Fig. 1). The training was conducted in 6 sessions. Surgeons' experience with video games and limb dominance were evaluated.

1. Opening the peritoneum with the peritoneal space creation

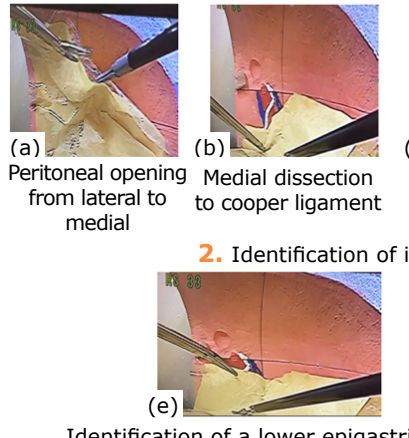

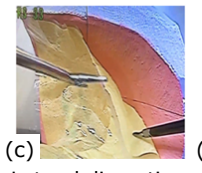

Lateral dissection pain triangle

mportant structures

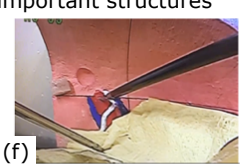

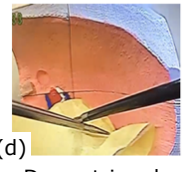

Doom triangle dissection
Identification of a lower epigastric/gonodal vessels/vas deferens

3. Hernia identification and reduction
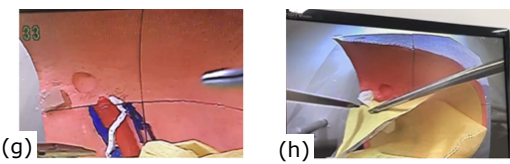

ernial failure identification Hernial sac reduction

4. Mesh position and fixation

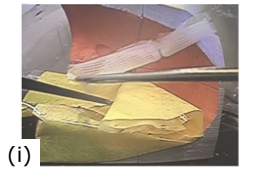

Proper mesh introduction by troca

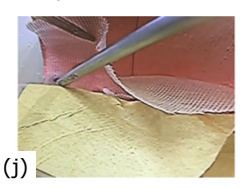
Proper mesh opening

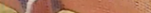
on the cooper ligament and 1 on the lateral
Fixation with 1 clamp

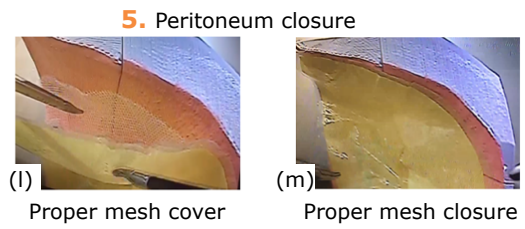

Figure 1 - Systematic curriculum of surgical technical execution. 


\section{Eligibility criteria}

For EG, surgeons who were in the second year of the General Surgery residency at a hospital at Fortaleza; be interested in the laparoscopic access route; have mastery over basic laparoscopic skills were included; for SG, surgeons who perform laparoscopy, but have no experience with inguinal hernia repair TAPP were included; and for CG, surgeons who have performed at least 60 TAPP inguinal hernioplasties were included.

The surgeons who didn't complete the proposed training within six weeks; were not present during all training sessions; didn't complete the forms and terms requested by the researcher; and didn't have time compatibility were excluded.

\section{D model development and simulator adjustments}

The first step was the collection of anatomical images in an atlas of human anatomy. The second step was the application of image patterns in the Blender software, version 2.79 , used in the Windows 10 operating system. This anatomy was applied as a reference in a model file called Male Pelvis Section from TurboSquid. The third step involved the printing and suitability 3D prototype enabling the best way to realistic simulation.

The failure making in the 3D model simulating direct inguinal hernia was created by applying a sphere-shaped Boolean modifier to the pelvis model with the difference operation to remove from it the intersection part between the pelvis and the previously created sphere. In order to paint the model, two flat Condor brushes and gouache ink were used, using the standard colors, according to the anatomy books to characterize the structures present in the model.

Next, a synthetic rubber was fixed very close to the hernial defect to simulate Cooper's ligament allowing the stapler to tackers, fixing the mesh as the real one. The next step in the model construction consisted in making adhesive structures that simulated the pelvic peritoneum and thus allowed the opening time of the peritoneum in the technique execution. For this, masking tape and Contact adhesive paper were used, covering the entire internal model's part, corresponding to the abdominal cavity and its peritoneum. Initially, there was a difficulty in adapting the material to the model's surface as well as how much should be covered from the interior of the model (Fig. 2). After a critical analysis by the researcher, the best measures to coat the model were determined.

In order to represent the hernial sac and its content to be reduced, a surgical time also important during the technique execution, it was used a latex glove inserted in the failure built in the model and adhered to the masking tape and Contact adhesive. In the model, it was possible to see the anatomical structures through transparency of masking tape and Contact adhesive, as well as in the real procedure. Once the model's construction was finished, it was decided to call it HerniLap 3D (Fig. 3).

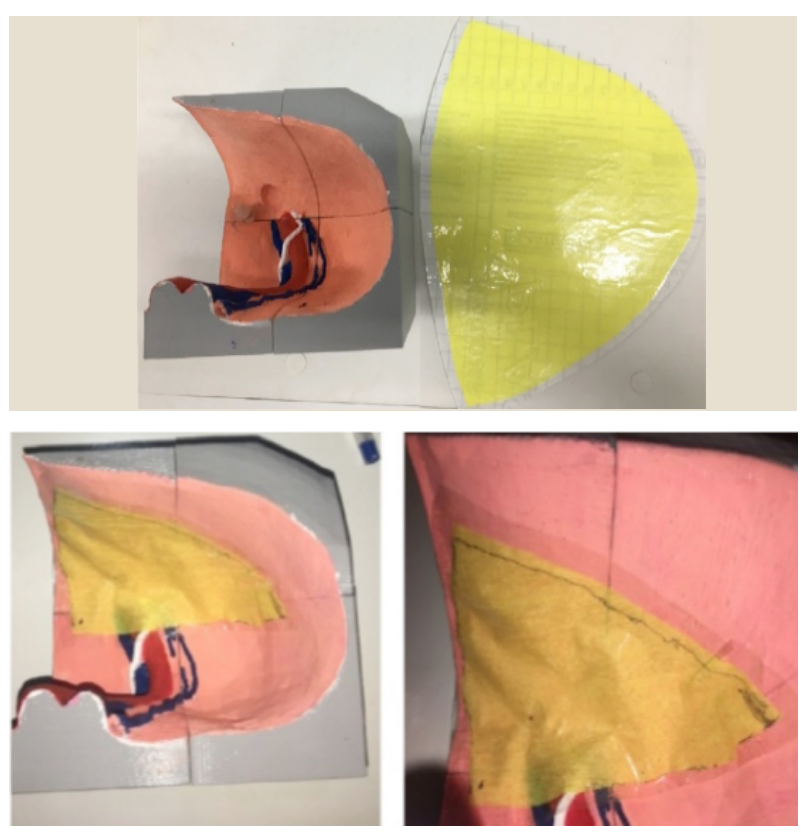

Figure 2-3D model with material apposition representing the peritoneum.
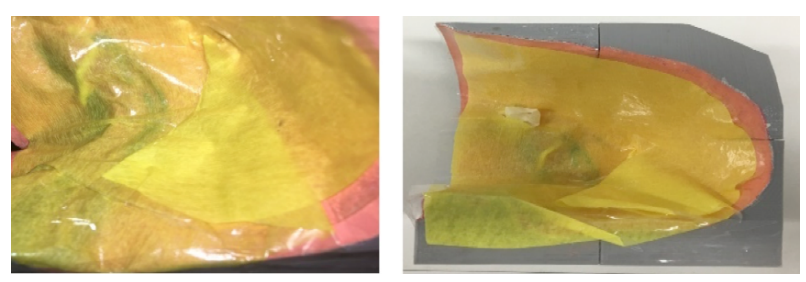

Figure 3-3D model with a glove representing the hernial sac.

The last step was the placement of the model inside the simulator, located in the LSS. The best position, distance of the trocars and camera position were seen to represent the simulation as real as possible. After finishing the model making four similar prototypes were reproduced.

\section{Statistical analysis}

Categorical data were expressed as absolute and percentage frequencies and compared by Fisher's exact test or Pearson's chi-square. The quantitative data were expressed as mean and standard deviation and compared among groups by the Kruskal-Wallis test and within the same group for the Friedman test measures both followed by the Bonferroni posttest. All analyzes were performed using $95 \%$ confidence 
in the Statistical Packing for Social Sciences (SPSS) version 20.0 software for Windows.

\section{Results}

Table 1 represents the descriptive analysis of the surgeons, in the EG group, $75.0 \%$ were men, in GS66.7\% and in CG 50.0\%.
Regarding the dominant hand, all participating surgeons from the three groups were right-handed. In the video games practice only $58.3 \%$ of the $E G$ group and $66.7 \%$ of the $\mathrm{SG}$ play them for more than $3 \mathrm{~h}$. In the TAPP technique, no surgeon in training demonstrated confidence in performing the technique.

Table 1 - Sociodemographic characteristics, surgical and physical experience of the participants.

\begin{tabular}{|c|c|c|c|c|c|c|c|}
\hline \multirow{2}{*}{ Variables } & \multicolumn{6}{|c|}{ Surgeon group } & \multirow{2}{*}{ P-value } \\
\hline & \multicolumn{2}{|c|}{ EG } & \multicolumn{2}{|c|}{ SG } & \multicolumn{2}{|c|}{ CG } & \\
\hline Age (years) & \multicolumn{2}{|c|}{$29.00 \pm 2.73+$} & \multicolumn{2}{|c|}{$34.67 \pm 1.53+$} & \multicolumn{2}{|c|}{$40.50 \pm 6.36 \dagger$} & - \\
\hline \multicolumn{8}{|l|}{ Sex } \\
\hline Male & 9 & $75.0 \%$ & 2 & $66.7 \%$ & 1 & $50.0 \%$ & \multirow{2}{*}{0.762} \\
\hline Female & 3 & $25.0 \%$ & 1 & $33.3 \%$ & 1 & $50.0 \%$ & \\
\hline \multicolumn{8}{|l|}{ Dominant hand } \\
\hline Right-handed & 12 & $100.0 \%$ & 3 & $100.0 \%$ & 2 & $100.0 \%$ & \multirow{2}{*}{1.000} \\
\hline Left-handed & 0 & $0.0 \%$ & 0 & $0.0 \%$ & 0 & $0.0 \%$ & \\
\hline \multicolumn{8}{|l|}{ Game (more than $3 \mathrm{~h} /$ week) } \\
\hline No & 5 & $41.7 \%$ & 1 & $33.3 \%$ & 2 & $100.0 \%$ & \multirow{2}{*}{0.270} \\
\hline Yes & 7 & $58.3 \%$ & 2 & $66.7 \%$ & 0 & $0.0 \%$ & \\
\hline \multicolumn{8}{|l|}{ Ability with musical instrument } \\
\hline No & 11 & $91.7 \%$ & 1 & $33.3 \%$ & 2 & $100.0 \%$ & \multirow{2}{*}{0.047} \\
\hline Yes & 1 & $8.3 \%$ & 2 & $66.7 \%$ & 0 & $0.0 \%$ & \\
\hline \multicolumn{8}{|l|}{ Specialty } \\
\hline General surgery & 12 & $100.0 \%$ & 1 & $100.0 \%$ & 0 & $100.0 \%$ & \multirow{2}{*}{0.001} \\
\hline Others & 0 & $0.0 \%$ & 2 & $66.7 \%$ & 2 & $100.0 \%$ & \\
\hline \multicolumn{8}{|c|}{ Which laparoscopic procedures have confidence in performing } \\
\hline Cholecystectomy & 5 & $41.7 \%$ & 3 & $100.0 \%$ & 2 & $100.0 \%$ & 0.084 \\
\hline Appendectomy & 3 & $25.0 \%$ & $3 *$ & $100.0 \%$ & $2 *$ & $100.0 \%$ & 0.019 \\
\hline Hernioplasty & 0 & $0.0 \%$ & 0 & $0.0 \%$ & $2 *$ & $100.0 \%$ & $<0.001$ \\
\hline Fundoplication & 0 & $0.0 \%$ & 1 & $33.3 \%$ & $2 *$ & $100.0 \%$ & 0.002 \\
\hline Residence time/performance & \multicolumn{2}{|c|}{$11.67 \pm 7.69$} & \multicolumn{2}{|c|}{$64.00 \pm 18.33^{*}$} & \multicolumn{2}{|c|}{$150.00 \pm 42.43^{*}+$} & $<0.001$ \\
\hline $\begin{array}{l}\text { Estimated observation time/assistance with video } \\
\text { surgery (hours) }\end{array}$ & \multicolumn{2}{|c|}{$192.50 \pm 321.59$} & \multicolumn{2}{|c|}{$4253.33 \pm 1397.33^{*}$} & \multicolumn{2}{|c|}{$12000.00 \pm 2828.43^{*}+$} & $<0.001$ \\
\hline $\begin{array}{l}\text { Estimated time of previous training in simulators } \\
\text { (hours) }\end{array}$ & \multicolumn{2}{|c|}{$15.83 \pm 27.46$} & \multicolumn{2}{|c|}{$63.33 \pm 40.41^{*}$} & \multicolumn{2}{|c|}{$425.00 \pm 106.07^{*}+$} & $<0.001$ \\
\hline $\begin{array}{l}\text { Estimated time of previous operating room training } \\
\text { (hours) }\end{array}$ & 82.3 & 137.60 & 600.0 & $100.00 *$ & 4720 & $=1244.51 *+$ & $<0.001$ \\
\hline Number of TAPP hernias performed & 0.0 & \pm 0.29 & 0.6 & 1.15 & 390 & $=339.41 *+$ & $<0.001$ \\
\hline Laparoscopy experience time (months) & 12. & \pm 8.71 & 680 & $13.86 *$ & 150 & $\pm 42.43^{*}+$ & $<0.001$ \\
\hline
\end{tabular}

*Friedman/Dunn Test, +Kruskal-Wallis/Dunn Test (mean \pm standard deviation). 
Table 2 describes the relationship of the learning curve between the first session and the final session in the three groups. It was possible to observe that there was no significant difference among the groups, only within the EG group that were the surgeons in training. The evolution of the mean laparoscopic skills scores during the sessions can also be observed in Table 2. The skills

Table 2 - Learning curve and procedure time of surgeons in training during training sessions.

\begin{tabular}{|c|c|c|c|c|}
\hline & & Training & sessions & \\
\hline & & S1 & s6 & p-Value \\
\hline & EG & $1.25 \pm 0.42 \mathrm{aA}$ & $3.25 \pm 0.62 b B$ & $0.002 *$ \\
\hline 1st stage & SG & $3.33 \pm 0.57 \mathrm{~B}$ & $0.285 \dagger$ & \\
\hline & CG & $4.00 \pm 0.00 \mathrm{~B}$ & & \\
\hline P-value & & $<0.001 \dagger$ & & \\
\hline & EG & $1.08 \pm 0.67 a A$ & $2.58 \pm 0.51 \mathrm{cB}$ & $0.019 *$ \\
\hline 2nd stage & SG & $2.58 \pm 0.31 \mathrm{~B}$ & $0.263+$ & \\
\hline & CG & $3.00 \pm 0.00 \mathrm{~B}$ & & \\
\hline P-value & & $<0.001+$ & & \\
\hline & EG & $1.00 \pm 0.43 a A$ & $2.08 \pm 0.29 c B$ & $0.004 *$ \\
\hline 3rd stage & SG & $2.00 \pm 0.00 \mathrm{~B}$ & $0.831+$ & \\
\hline & CG & $2.00 \pm 0.00 \mathrm{~B}$ & & \\
\hline P-value & & $0.001 \dagger$ & & \\
\hline & EG & $1.08 \pm 0.67 a A$ & $2.92 \pm 0.29 b B$ & $<0.001^{*}$ \\
\hline 4th stage & SG & $2.67 \pm 0.58 \mathrm{~B}$ & $0.468+$ & \\
\hline & CG & $3.00 \pm 0.00 \mathrm{~B}$ & & \\
\hline P-value & & $0.001 \dagger$ & & \\
\hline & EG & $0.91 \pm 0.29^{a} \mathrm{~A}$ & $1.91 \pm 0.29 b B$ & $<0.001^{*}$ \\
\hline 5th stage & SG & $2.00 \pm 0.00 B$ & $0.831 \dagger$ & \\
\hline & CG & $2.00 \pm 0.00 \mathrm{~B}$ & & \\
\hline P-value & & $<0.001+$ & & \\
\hline & EG & $1.08 \pm 0.29 a A$ & $3.50 \pm 0.90 \mathrm{cC}$ & $<0.001^{*}$ \\
\hline $\begin{array}{l}\text { Laparoscopic } \\
\text { skills }\end{array}$ & SG & $5.00 \pm 0.00 \mathrm{~B}$ & $0.012+$ & \\
\hline & CG & $5.00 \pm 0.00 \mathrm{~B}$ & & \\
\hline P-value & & $<0.001 \dagger$ & & \\
\hline & EG & $7.82 \pm 3.74 a A$ & $4.73 \pm 2.62 \mathrm{aB}$ & $0.555^{*}$ \\
\hline Time (min) & SG & $4.74 \pm 1.79 B$ & $0.918+$ & \\
\hline & CG & $3.98 \pm 0.58 \mathrm{~B}$ & & \\
\hline P-value & & $0.204 \dagger$ & & \\
\hline & EG & $4.89 \pm 0.92 \mathrm{aA}$ & $14.22 \pm 0.97 \mathrm{dC}$ & $<0.001^{*}$ \\
\hline Score & SG & $15.00 \pm 0.00 B$ & $0.039+$ & \\
\hline & CG & $16.00 \pm 0.00 B$ & & \\
\hline $\mathrm{P}$-value & & $<0.001 \dagger$ & & \\
\hline
\end{tabular}

*Friedman / Dunn test, + Kruskal-Wallis / Dunn test (mean \pm standard deviation). Different lowercase letters $=$ significant difference between assessment moments, Different uppercase letters $=$ Significant difference between groups. evaluated during the execution of the technique were four: ambidexterity, stereotaxis, hapticity and central effect, each corresponding to one point. The surgeons in training presented in the first session an average of $1.08 \pm 0.29$ and in the sixth of $3.50 \pm 0.90(p=0.001)$.

\section{Discussion}

Even though it is hardly used in regions with limited health resources, TAPP laparoscopic correction has recurrence rates equal to or lower than previous repairs associated with the benefit of low morbidity with rapid work return ${ }^{15}$. Transabdominal preperitoneal inguinal hernia repair rates range from 10 to $48 \%{ }^{16}$, and almost half of surgeons had never performed laparoscopic repair, corroborated by this study, in which only two surgeons in training had performed / assisted a laparoscopic hernia ${ }^{13}$.

Participants in this study describe the need for TS in the first year of training. As in the study by Chipman et $a l .{ }^{17}$ and Schmidt et al. ${ }^{18}$, who say that a good surgical curriculum training with the best technical training possible should be introduced as early as possible in the surgeon's training. Among surgeons in training, 75\% report that the frequency of the simulation should take place every two weeks. Trevisonno et al. ${ }^{13}$ state that both experienced and in-training surgeons should perform simulated training followed by supervised procedure only after it can be performed without external intervention.

Within EG group, $58 \%$ of participants reported that their previous gaming activities shortened their laparoscopic skills, which did not show statistical significance and the literature also has conflicting data when stating that video games shorten the curve. The biggest gain seems to be related to the psychomotor component ${ }^{18-21}$. It is known that the resting period is important for the retention of psychomotor skills as stated ${ }^{22}$.

The insertion of a systematized curriculum allows the training surgeon to easily and quickly identify the steps of the technique execution ensuring a greater confidence in performing the procedure with objectivity and safety for the patient. Systematizing simulation training enables the construction of performance evaluation tools allowing the technique validation for Cristancho et al. ${ }^{23}$.

In this study, the TS lasted six consecutive weeks, each session being short, with an average of $15 \mathrm{~min}$. According to Mitchell et al. ${ }^{24}$, the ideal simulation program should consist of sessions that do not exceed one hour and have weekly intervals, as these conditions are associated with the keeping and improvement of newly acquired skills.

As going through the six sessions, the surgeon in training acquired the skills through of the curriculum systematic 
training, a fact already noticeable, with statistical difference from the third session that progresses further in the sixth session. When comparing the three groups after the sixth session, the surgeon in training already has expertise comparable to the other groups, without statistical difference.

Regarding the time, although surgeons in training have a decreasing average time, it has no statistical difference when compared to each other in the first and last session and when compared to the sixth session with the other two groups. It can be inferred that perhaps the execution beyond six sessions in any given session will present statistical difference when comparing each other and between groups.

\section{Conclusions}

The developed 3D model used low-cost material and was easy to reproduce, which allowed a systematization, facilitating the method of the TAPP laparoscopic repair technique through the use of the curriculum, allowing the training surgeon to gain upward laparoscopic skills equipping the surgeons with or without experience after the simulation sessions. The results comparison of the execution in each stage of the curriculum among the groups showed no significance, but in the first session of the EG group, to the last, it was possible to observe a significant improvement, demonstrating the effectiveness of the 3D model and the systematized curriculum developed.

\section{Authors' contribution}

Substantial scientific and intellectual contributions to the study: Melo Filho LP and Borges GCO; Conception and design: Melo Filho LP and Almeida AM; Acquisition, analysis and interpretation of data: Melo Filho LP; Technical procedures: Melo Filho LP; Histopathological examinations: Melo Filho LP; Statistics analysis: Melo Filho LP; Manuscript preparation and writing: Melo Filho LP; Critical revision: Melo Filho LP, Barros Filho EM and Borges GCO; Final approval: Barros Filho EM and Borges GCO.

\section{Data availability statement}

Data will be available upon request.

\section{Funding}

Not applicable.

\section{Acknowledgments}

We would like to thank to Santa Casa de Misericórdia de Fortaleza and to Centro Universitário Christus - Unichristus.

\section{References}

1. Chen DC, Morrison J. State of the art: open mesh-based inguinal hernia repair. Hernia. 2019;23(3):485-92. https:// doi.org/10.1007/s10029-019-01983-z

2. Sereysky J, Parsikia A, Stone ME, Castaldi M, McNelis J. Predictive factors for the development of surgical site infection in adults undergoing initial open inguinal hernia repair. Hernia. 2019;24(1):173-8. https://doi. org/10.1007/s10029-019-02050-3

3. Ruhl CE, Everhart JE. Risk factors for inguinal hernia among adults in the US population. Am J Epidemiol. 2007;165(10):1154-61. https://doi.org/10.1093/aje/kwm011

4. Bosi HR, Guimaraes JR, Cavazzola LT. Robotic assisted single site for bilateral inguinal hernia repair. ABCD Arq Bras Cir Dig. 2016;29(2):109-11. https://doi.org/10.1590/01026720201600020011

5. Ger R, Monroe K, Duvivier R, Mishrick A. Management of indirect inguinal hernias by laparoscopic closure of the neck of the sac. Am J Surg. 1990;159(4):370-3. https:// doi.org/10.1016/S0002-9610(05)81273-5

6. Arregui ME, Davis CJ, Yucel O, Nagan RF. Laparoscopic mesh repair of inguinal hernia using a preperitoneal approach: a preliminary report. Surg Laparosc Endosc. 1992;2(1):53-8.

7. Droeser RA, Dell-Kuster S, Kurmann A, Rosenthal R, Zuber M, Metzger J, Oertli D, Hamel CT, Frey DM. Long-term follow-up of a randomized controlled trial of Lichtenstein's operation versus mesh plug repair for inguinal hernia. Ann Surg. 2014;259(5):966-72. https://doi.org/10.1097/ SLA.0000000000000297

8. Hayashi Y, Miyata K, Yuasa N, Takeuchi E, Goto Y, Miyake H, Nagai $\mathrm{H}$, Kobayashi Y. Short- and long-term outcomes of open inguinal hernia repair: comparison of the Prolene Hernia System and the Mesh Plug method. Surg Today. 2014;44(12):2255-62. https:// doi.org/10.1007/s00595-014-0867-7

9. Takahashi T, Kaneoka Y, Maeda A, Takayama Y, Fukami Y, Uji M. Feasibility study of open inguinal hernia repair using mesh plug by residents. Asian J Surg. 2020;43(1):304-10. https://doi.org/10.1016/j.asjsur.2019.05.011

10. Meyer A, Dulucq J-L, Mahajna A. Correção de hérnia laparoscópica: tela sem fixação é viável? $A B C D$ Arq Bras Cir Dig. 2013;26(1):27-30. https://doi.org/10.1590/ S0102-67202013000100006

11. Nicole N, Rachel C, Michael M, Ross B, Sue G, Allison V, Colleen F. Robotic assisted, total laparoscopic, and total abdominal hysterectomy for management of uterine cancer. J Cancer Ther. 2012;3(2):162-6. https://doi.org/10.4236/jct.2012.32022

12. Mikhin IV, Polyakov AA, Kosivtsov OA, Ryaskov LA. Endoscopic surgery and laparoscopy are new insights of evolution of inguinal hernia repair. Khirurgiia (Mosk). 2019;3:121-8. https://doi.org/10.17116/hirurgia2019031121 
13. Trevisonno $M$, Kaneva $P$, Watanabe $Y$, Fried $G M$, Feldman LS, Lebedeva E, Vassiliou MC. A survey of general surgeons regarding laparoscopic inguinal hernia repair: practice patterns, barriers, and educational needs. Hernia. 2015;19(5):719-24. https://doi.org/10.1007/s10029-014-1287-8

14. Stefanidis D, Acker CE, Greene FL. Performance goals on simulators boost resident motivation and skills laboratory attendance. J Surg Educ. 2010;67(2):66-70. https://doi. org/10.1016/j.jsurg.2010.02.002

15. Neumayer L, Giobbie-Hurder A, Jonasson O, Fitzgibbons Junior R, Dunlop D, Gibbs J, Reda D, Henderson W. Open mesh versus laparoscopic mesh repair of inguinal hernia. N Engl J Med. 2004;350(18):1819-27. https://doi. org/10.1056/NEJMoa040093

16. Vu JV, Gunaseelan V, Krapohl GL, Englesbe MJ, Campbell Junior DA, Dimick JB, Telem DA. Surgeon utilization of minimally invasive techniques for inguinal hernia repair: a population-based study. Surg Endosc. 2019;33(2):486-93. https://doi.org/10.1007/s00464-018-6322-x

17. Chipman JG, Schmitz CC. Using objective structured assessment of technical skills to evaluate a basic skills simulation curriculum for first-year surgical residents. J Am Coll Surg. 2009;209(3):364-70. https://doi.org/10.1016/j. jamcollsurg.2009.05.005

18. Schmidt L, Andresen K, Rosenberg J. No difference in genitourinary complications after laparoscopic vs. open groin hernia repair in women: a nationwide linked registerbased cohort study. Surg Endosc. 2020;34(5):1978-84. https://doi.org/10.1007/s00464-019-06973-x

19. Kennedy M, Barrera K, Akelik A, Constable $Y$, Smith $M$, Chung P, Sugiyama G. Robotic TAPP ventral hernia repair: early lessons learned at an inner city safety net hospital. JSLS. 2018;22(1):e2017.00070. https://doi.org/10.4293/ JSLS.2017.00070

20. Paschold M, Schröder M, Kauff DW, Gorbauch T, Herzer M, Lang $H$, Kneist W. Virtual reality laparoscopy: which potential trainee starts with a higher proficiency level? Int J Comput Assist Radiol Surg. 2011;6(5):653-62. https:// doi.org/10.1007/s11548-010-0542-4

21. Verdaasdonk EGG, Stassen LPS, van Wijk RPJ, Dankelman J. The influence of different training schedules on the learning of psychomotor skills for endoscopic surgery. Surg Endosc. 2007;21(2):214-9. https://doi.org/10.1007/ s00464-005-0852-8

22. Cristancho SM, Moussa F, Dubrowski A. A framework-based approach to designing simulation-augmented surgical education and training programs. Am J Surg. 2011;202(3):34451. https://doi.org/10.1016/j.amjsurg.2011.02.011

23. Mitchell JBO. Informatics, machine learning and computational medicinal chemistry. Future Med Chem. 2011;3(4):451-67. https://doi.org/10.4155/fmc.11.11 